\title{
URINARY TRACT INFECTION IN PREGNANT FEMALES ATTENDING ANTENATAL CLINICS AMONG MIDDLE SOCIOECONOMIC SETTINGS.
}

1. MBBS, FCPS Assistant Professor Nephrology Fazaia Ruth Pfau Medical College. 2. MBBS, FCPS

Assistant Professor Gynaecology and Obstetrics

Jinnah Medical and Dental College.

3. MBBS, MPH

Senior Lecturer Community

Medicine

Jinnah Medical and Dental College.

Correspondence Address:

Dr. Mahjabeen Yaseen

Department of Nephrology

Fazaia Ruth Pfau Medical College.

dr.mahjabeenyaseen@gmail.com

Article received on:

25/11/2019

Accepted for publication:

01/01/2020

\section{Mahjabeen Yaseen ${ }^{1}$, Sadia Rashid ${ }^{2}$, Shagufta Naqvi ${ }^{3}$}

ABSTRACT... Objectives: To determine the frequency of Urinary tract infection (UTI) and the antibiotic sensitivity patterns of isolated uropathogens in pregnant females among middle socioeconomic settings. Study Design: Retrospective Cross Sectional study. Setting: Jinnah Medical College Hospital Karachi. Period: From Jan 2017 to Dec 2017. Material \& Methods: All the pregnant women who were registered in antenatal clinics from January 2017 to December 2017 WERE included. Results: Five hundred and sixty-four pregnant women of age 17-44 years were registered in the hospital in antenatal clinics during the year 2017. Out of 564 females, $48(8.50 \%)$ presented with urinary tract infection some time during their pregnancy period. Majority of patients $(54.2 \%)$ were infected with Escherichia coli (E coli), followed by Klebsiella pneumonia (16.77\%), Pseudomonas spp. (12.5\%), Enterococcus spp. $(8.3 \%)$ and Staphylococus aureus (8.3\%). These etiologic agents vary in their sensitivity pattern to antibiotics. Piperacillin-tazobactam had the highest overall sensitivity of $(89.6 \%)$. This was followed by Meropenem (87.5\%), Nitrofurantoin (87.5\%) and Fosfomycin (81.3\%). Cefixime, Cefotaxime and Amoxicillin/ clavulanic acid had overall sensitivities above $50 \%$. Conclusion: E coli was the common organisms followed by others gram negative and positive organisms. Enteroococus spp. was also a significant bacterial isolates in this settings. Meropenem, Piperacillin-tazobactam, Nitrofurantoin, Fosfomycin were the highly effective antibiotics against isolated uropathogens. Amoxicillin/clavulanic acid and Cephalosporin also had a good results.

Key words: Antibiotics Sensitivity Pattern, Pregnancy, Urinary Tract Infection, Uropathogens.

Article Citation: Yaseen M, Rashid S, Naqvi S. Urinary tract infection in pregnant females attending antenatal clinics among middle socioeconomic settings. Professional Med J 2020; 27(8):1636-1641.

DOI: 10.29309/TPMJ/2020.27.08.4357

\section{INTRODUCTION}

Urinary tract infection (UTI) is the most commonest infectious diseases in under developed countries annually the estimated incidence is 250 million. ${ }^{1}$

In pregnant females UTI is commonly observed in 6 to 24 weeks. $^{2}$ It is the common reason for hospitalization and $20 \%$ of females have been affected with UTI in their gestational period. $28 \%$ of pregnant women with UTI have signs and symptoms of UTI while $71.9 \%$ have no symptoms. ${ }^{3}$ Short length of urethra, lack of secretions from prostate gland, close anatomical structure of urethra and anal region, poor hygienic conditions, increase frequency of sexual intercourse, high parity, age, low socioeconomic status, functional and anatomic disorders of urinary tract, diabetes mellitus, poor control of glucose during pregnancy, neurogenic bladder are the risk factors for increase prevalence of UTI. ${ }^{4}$

Pregnant females are likely to get UTI due to some other factors as well which include decreased tonicity of bladder and ureter, dilatation of ureters, increased bladder volume .All these factors contributes to stasis of urine and increase vesicoureteral reflux. ${ }^{5}$

Preterm labor, low birth weight babies, intrauterine deaths, chronic kidney diseases, anemia, kidney infections, hypertension during pregnancy are the complications of UTI in pregnancy. To avoid these complications UTI have to be treated timely in pregnant females. ${ }^{6}$ 
Microorganisms of UTI are almost same in pregnant and non-pregnant females. Escherichia coli causing $90 \%$ of the infection. ${ }^{7}$ Remaining infections are caused by Pseudomonas spp. and Klebsiella pneumonia.

Since last few years there is an increase in the resistance of antimicrobial drugs of UTI. For a good and proper management of UTI in pregnant females it is necessary for the Nephrologist, Physicians and Obstetricians to know about the common etiologic organisms of UTI and their patterns of antibiotic sensitivity.

So empirical treatment can be started before the availability of final sensitivity results.

Currently Local data on the etiological organisms of UTI and their susceptibility to antibiotics is scarce. Therefore this study aims to explore the pattern of UTI causing organisms and their susceptibility to antibiotics in pregnant females attending antenatal clinics of Jinnah Medical College Hospital (JMCH).

\section{MATERIAL \& METHODS}

This study was carried out at Jinnah Medical College Hospital (JMCH) Karachi after ethical review committee approval. This was a descriptive cross sectional study of pregnant females who were registered at the antenatal clinic of $\mathrm{JMCH}$ and underwent urinary culture and sensitivity analysis. All pregnant females who had attended the antenatal clinic from January 2017 to December 2017 were included. Those who had Congenital or acquired urinary tract abnormality and renal stone diseases were excluded. Data was taken from Medical record department and information about age, parity, gravida, miscarriages, microorganisms from the urine samples and their antibiotic susceptibility pattern was noted in a study Performa.

Data was entered and analyzed using the SPSS (version 25). Descriptive analysis was used for the socio-demographic characteristic and other variables.

\section{RESULTS}

Total 564 participants were included in the study.
The mean age of women with UTI were 28.71 +5.458 . Majority were in the age group of 2029 years. UTI was observed more commonly in multiparous women. Out of 564 participants, 48(8.5\%) had a positive urine culture results. Table-l.

Isolated uropathogens isolated are presented in Table-II. Escherichia coli (E.coli) was the most common bacterial isolates accounting for 26 $(54.2 \%)$ of the total isolates. This was followed by Klebsiella pneumoniae which accounted for $8(16.7 \%)$ of the isolate. The frequency of the other bacterial isolates included Pseudomonas spp. 6 (12.5\%); Enterococcus spp. 4 (8.3\%); Staphylococcus aureus 4(8.3\%).

Overall antibiotic sensitivity pattern of bacterial isolates is shown in Table-III.

Piperacillin-tazobactam had the highest overall sensitivity of $89.6 \%$. This was closely followed by Meropenem $87.5 \%$. Nitrofurantoin and Fosfomycin had a sensitivity of $87.5 \%$ and $81.3 \%$ respectively. Cefixime, Cefotaxime and Amoxicillin/clavulanic acid had overall sensitivities above $50 \%$.

The antibiotic sensitivity pattern of uropathogens from UTI positive women is shown in Table-IV. E coli showed $100 \%$ sensitivity to Meropenem and Piperacillin-tazobactam, 92.3\% to Fosfomycin, $84.6 \%$ to Cefixime \& Nitrofurantoin, $77 \%$ to Amoxicillin/clavulanic acid, $73.1 \%$ to Amikacin and Cefotaxime, $53.8 \%$ to Ciprofloxacin and less than $50 \%$ sensitivity to other antibiotics. Klebsiella pneumoniae showed $100 \%$ sensitivity to Nitrofurantoin, Meropenem and Piperacillintazobactam, $75 \%$ to Fosfomycin, $62.5 \%$ to Amikacin, $50 \%$ to Amoxicillin/Clavulanic acid, Cefotaxime and Ciprofloxacin.

$100 \%$ of Pseudomonas spp. were sensitive to Cefotaxime, $83.3 \%$ to Piperacillin-tazobactam, Cefixime, Colomycin and Ciprofloxacin, $66.7 \%$ to Nitrofurantoin, Meropenem and Amikacin, 66\% to Amikacin, $50 \%$ to Fosfomycin, Cefotaxime and amoxicillin/Clavulanic acid.

$100 \%$ of the Staphylococus aureus were found 
to be sensitive to Amikacin, Nitrofurantoin and Fosfomycin and $75 \%$ to Vancomycin and Ciprofloxacin.

However $100 \%$ of Enterococcus spp. were sensitive to Fosfomycin, Amikacin, Nitrofurantoin, and Amoxicillin/Clavulanic acid, 75\% to Ampicillin, Vancomycin, and Piperacillin-tazobactam, Meropenem, Cefotaxime and Ciprofloxacin.

\begin{tabular}{|l|c|c|}
\hline \multicolumn{1}{|c|}{ Variables } & $\begin{array}{c}\text { Pregnant woman } \\
\text { with } \\
\text { Positive culture } \\
\text { (n =48) } \\
\mathbf{n}(\%)\end{array}$ & $\begin{array}{c}\text { Pregnant woman } \\
\text { with } \\
\text { Negative culture } \\
\text { (n =516) } \\
\mathbf{n}(\%)\end{array}$ \\
\hline Age & & \\
\hline$<20$ & $5(10.4)$ & $46(8.9)$ \\
\hline $20-29$ & $22(45.8)$ & $305(59.1)$ \\
\hline $30-39$ & $21(43.8)$ & $165(32)$ \\
\hline Parity & & \\
\hline Primigravida & $15(31.3)$ & $143(27.7)$ \\
\hline Primipara & $7(14.6)$ & $149(28.9)$ \\
\hline Multi para & $20(41.7)$ & $178(34.5)$ \\
\hline Grand multipara & $6(12.5)$ & $46(8.8)$ \\
\hline
\end{tabular}

Table-I. Socio-demographic characteristics of pregnant women:

\begin{tabular}{|l|c|c|}
\hline \multicolumn{1}{|c|}{ Organisms } & $\begin{array}{c}\text { Numbers } \\
\text { (n) }\end{array}$ & $\begin{array}{c}\text { Percentage } \\
\text { (\%) }\end{array}$ \\
\hline E.coli & 26 & 54.2 \\
\hline Klebsiella pneumoniae & 8 & 16.7 \\
\hline Pseudomonas spp. & 6 & 12.5 \\
\hline Enterococcus spp. & 4 & 8.3 \\
\hline Staphylococcus aureus. & 4 & 8.3 \\
\hline
\end{tabular}

Table-II. Organisms isolated from pregnant women with urinary tract infection:

\begin{tabular}{|l|c|c|}
\hline \multicolumn{1}{|c|}{ Antibiotics } & $\begin{array}{c}\text { Frequency } \\
\text { (n) }\end{array}$ & $\begin{array}{c}\text { Sensitive } \\
\text { (\%) }\end{array}$ \\
\hline Piperacillin-tazobactam & 43 & 89.6 \\
\hline Meropenem & 42 & 87.5 \\
\hline Nitrofurantoin & 42 & 87.5 \\
\hline Fosfomycin & 39 & 81.3 \\
\hline Cefixime & 33 & 68.8 \\
\hline Cefotaxime & 32 & 66.7 \\
\hline Amoxicillin clavulanic acid & 28 & 58.3 \\
\hline Ciprofloxacin & 27 & 56.3 \\
\hline Ampicillin & 15 & 31.3 \\
\hline Ofloxacin & 3 & 6.3 \\
\hline
\end{tabular}

Table-III. Overall antibiotics sensitivity pattern (irrespective of bacterial isolates) to the isolated organisms $(n=48)$

\section{DISCUSSION}

Along with anemia and hypertension in pregnancy, UTI is also commonly found and affects $5-10 \%$ of pregnancies. In this study we found $8.5 \%$ of positive urine culture reports in pregnant females. This is in agreement with the Sevki et al who reported a prevalence rate of $8.5 \%{ }^{8}$ Prevalence rate reported by Agersew et al (10.4\%) and Getachew et al (12\%) are also consistent with our study results..$^{9,10}$

Furthermore the prevalence rate of our study is not match with studies done in Ibadan SouthWestern Nigeria who reported a prevalence rate of $45.7 \%$ and in Amassoma Southern Nigeria who reported a prevalence rate of $25.3 \%$ respectively which is higher than our results. ${ }^{11,12}$ This high prevalence is may be due to low socio-economic status, deficient environmental cleanliness, lack of awareness and practices of personal hygiene and increased frequency of sexual intercourse.

In our study gram-negative bacteria was more commonly observed than gram-positive bacteria and $\mathrm{E}$ coli is the commonest one which is similar to many other studies. ${ }^{1,9,10}$

Second common pathogen in this study is Klebsiella pneumonia (16.7\%) which is opposite to many other studies that reported Staphylococcus aureus is the second common uropathogens. ${ }^{3,13}$

This variations in pattern of uropathogens might be due to the variations of environment, personal hygiene practice and social habits Karki and Derese reported $16.6 \%$ and $11.5 \%$ of Klebsiella species respectively. ${ }^{13,14}$

Third common uropathogens is Pseudomonas spp. $(12.5 \%)$ which is consistent with Derese. ${ }^{14}$

Staphylococcus aureus is reported as second common pathogen in many previous studies but in our study we found its prevalence is only $8.3 \%$ that is consistent with the Shazia et al. ${ }^{1}$

Majority of uropathogens causing UTI are gram negative bacteria and usually from the gastrointestinal tract. 


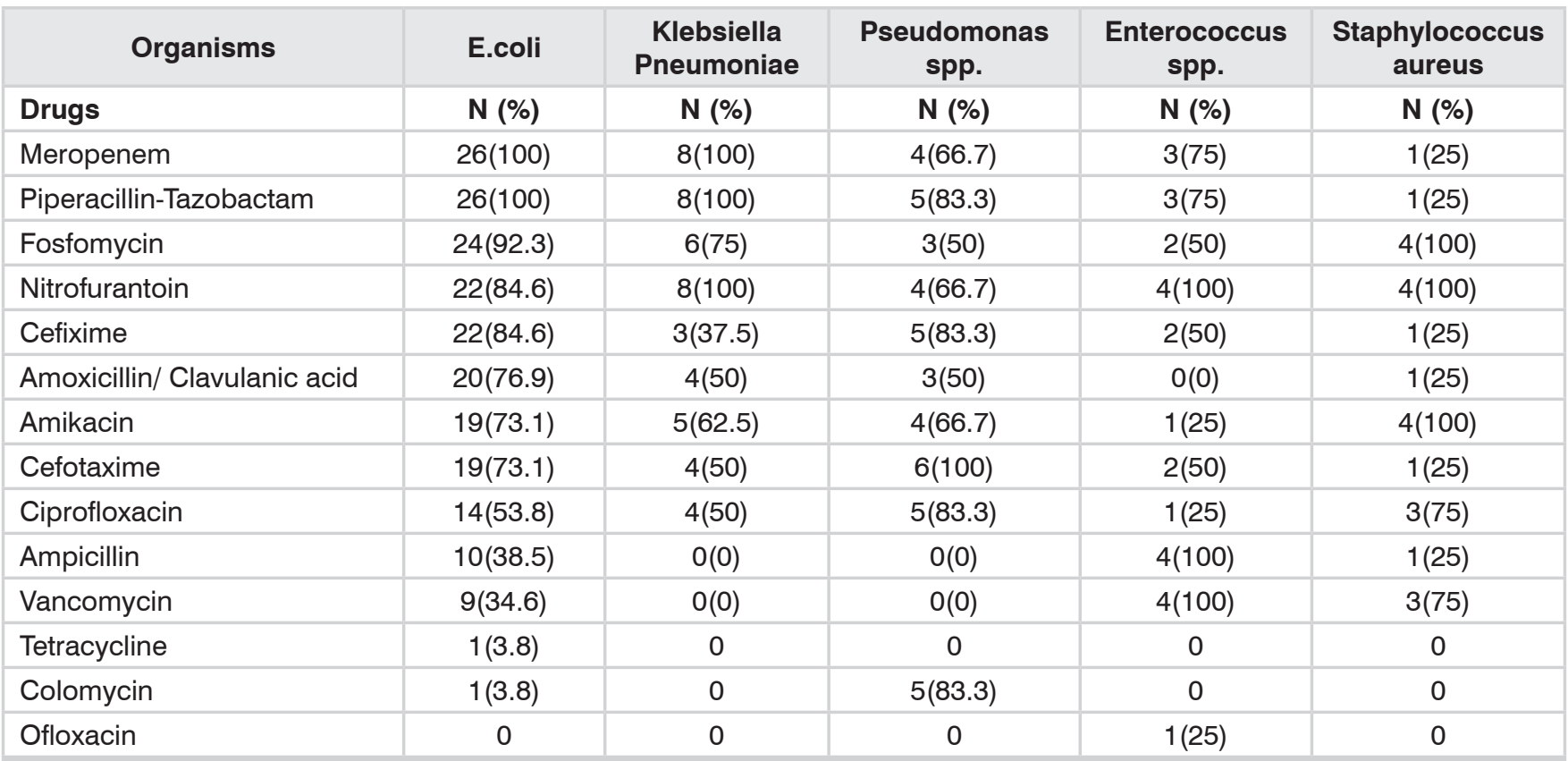

Table-IV. Antibiotic sensitivity pattern of uropathogens from UTI positive women.

In our study antibiotic with the overall high sensitivity pattern is Piperacillin-tazobactam which is consistent with the previous studies. ${ }^{15,16}$

Second one is Meropenem which is consistent with Rizvi et al and Patnik et al who reported a high sensitivities of uropathogens with Meropenem. ${ }^{17,18}$

Nitrofurantoin has a very good sensitivity pattern in our study .It is a cheap drug and could play a good role in the treatment of UTI. Studies done in Ethiopia and Tanzania also showed a similar results to our study. ${ }^{2,19}$

Fosfomycin have a very good results in our study and consistent with the study done previously. ${ }^{20}$ It is also a cheap drug and can also play a good role in management of UTI.

Cephalosporin also have a good results in our study which include Cefotaxime and Cefixime this is consistent with Subeidi et al. ${ }^{15}$

Our study also reported low sensitivity with Quinolones which is divergent with many studies done previously. ${ }^{21,22}$ High resistance to Quinolones and other antibiotics is due to over usage and practice of self-medication which leads to emergence of highly resistant organisms.

Amoxicillin/clavulanic acid also have a good results in our study. Similar findings was also evidenced in earlier studies. ${ }^{15,19}$

\section{LIMITATIONS OF THE STUDY}

This study was a hospital based and may not truly reflect the entire city. As this study was the analysis of cultures done prior to the study there is a lack of uniformity of antibiotic sensitivities results against uropathogens. The antibiotic susceptibility results against isolated microorganisms in the laboratory was an in-vitro activity and may not truly reveal the in-vivo activity.

\section{CONCLUSION}

E coli was the common organisms followed by others gram negative and positive organisms. Enteroococus spp. was also a significant bacterial isolates in this settings. Meropenem, Piperacillintazobactam, Nitrofurantoin, Fosfomycin were the highly effective antibiotics. These antibiotics could be administered empirically due to their high sensitivity results. Cost effective antibiotics still are the options in uncomplicated cases. Amoxicillin/ clavulanic acid and Cephalosporin also had a good results.

Copyright $@ 01$ Jan, 2020. 


\section{REFERENCES}

1. Parveen SS, Reddy SV, Rao MV, Rao JR. Uropathogens and their drug susceptibility patterns among pregnant women in a Teaching Hospital. Ann Biol Res. 2011; 2(5):516-21.

2. Moyo SJ, Aboud S, Kasubi M, Maselle SY. Bacterial isolates and drug susceptibility patterns of urinary tract infection among pregnant women at Muhimbili National Hospital in Tanzania. Tanzania Journal of Health Research. 2010; 12(4):233-6.

3. Hamdan Z. Ziad Abdel Haliem M, Ali Salah K, Ishag Adam. Epidemiology of urinary tract infections and antibiotics sensitivity among pregnant women at Khartoum North Hospital. Ann Clin Microbiol Antimicrob. 2011; 10 (2):1-5.

4. Haider G, Zehra N, Munir AA, Haider A. Risk factors of urinary tract infection in pregnancy. JPMA. The Journal of the Pakistan Medical Association. 2010 Mar $1 ; 60(3): 213$.

5. PriyankaH, TarunaS, Ruchira N. Pattern of antimicrobial use for urinary tract infection during pregnancy in a Tertiary Care Teaching Hospital. International Journal of Medical Research and Health Sciences. 2015 Jan 1; 4(2):386-90.

6. Loh $\mathrm{KY}$, Sivalingam N. Urinary tract infections in pregnancy. Malaysian family physician. 2007; 2(2):54.

7. Khan S, Singh P, Siddiqui Z, Ansari M. Pregnancyassociated asymptomatic bacteriuria and drug resistance. Journal of Taibah University Medical Sciences. 2015 Sep 1; 10(3):340-5.

8. Çelen Ş, Oruç AS, Karayalçin R, Saygan S, Ünlü S, Polat $B$ et al. Asymptomatic bacteriuria and antibacterial susceptibility patterns in an obstetric population. ISRN obstetrics and gynecology. 2011 Jan 24; 2011.

9. Alemu A, Moges F, Shiferaw Y, Tafess K, Kassu A, Anagaw $B$ et al. Bacterial profile and drug susceptibility pattern of urinary tract infection in pregnant women at University of Gondar Teaching Hospital, Northwest Ethiopia. BMC research notes. 2012 Dec; 5(1):197.

10. Ferede G, Yismaw G, Wondimeneh Y, Sisay Z. The prevalence and antimicrobial susceptibility pattern of bacterial uropathogens isolated from pregnant women. Eur J Exp Biol. 2012; 2(5):1497-502.

12. Okonko IO, ljandipe LA, llusanya OA, DonbrayeEmmanuel OB, Ejembi J, Udeze AO et al. Incidence of urinary tract infection (UTI) among pregnant women in Ibadan, South-Western Nigeria. African Journal of Biotechnology. 2009; 8(23).
13. Tolulope A, Deborah $O$. Urinary tract infection amongst pregnant women in Amassoma, Southern Nigeria. African journal of microbiology research. 2015 Feb 11; 9(6):355-9.

14. Karki A, Tiwari BR, Pradhan SB. Study of bacteria isolated from urinary tract infection and their sensitivity pattern. Journal of the Nepal Medical Association. 2004 Jul 1; 43(154).

15. Derese B, Kedir H, Teklemariam Z, Weldegebreal F, Balakrishnan S. Bacterial profile of urinary tract infection and antimicrobial susceptibility pattern among pregnant women attending at antenatal Clinic in Dil Chora Referral Hospital, Dire Dawa, eastern Ethiopia. Therapeutics and clinical risk management. 2016; $12: 251$.

16. Subedi N, Pudasaini S. Bacteriological profile and antibiotic sensitivity pattern in patients with urinary tract infection. Journal of Pathology of Nepal. 2017 Mar 30; 7(1):1066-9.

17. Niranjan V, Malini A. Antimicrobial resistance pattern in Escherichia coli causing urinary tract infection among inpatients. The Indian journal of medical research. 2014 Jun; 139(6):945.

18. Patnaik M, Panigrahi K, Das B, Pathi B, Poddar N, Lenka PR et al. Prevalence, risk factors and causative organisms of asymptomatic bacteriuria in pregnancy. International Journal of Advances in Medicine. 2017 Sep; 4(5):1348.

19. Rizvi M, Khan F, Shukla I, Malik A. Rising prevalence of antimicrobial resistance in urinary tract infections during pregnancy: Necessity for exploring newer treatment options. Journal of laboratory physicians. $2011 \mathrm{Jul} ; 3(2): 98$.

20. Assefa A, Asrat D, Woldeamanuel Y, Abdella A, Melesse T. Bacterial profile and drug susceptibility pattern of urinary tract infection in pregnant women at Tikur Anbessa Specialized Hospital Addis Ababa, Ethiopia. Ethiopian medical journal. 2008 Jul; 46(3):227-35.

21. Souza RB, Trevisol DJ, Schuelter-Trevisol F. Bacterial sensitivity to fosfomycin in pregnant women with urinary infection. Brazilian Journal of Infectious Diseases. 2015 Jun; 19(3):319-23.

22. Egbodo O, Edugbe A, Akunaeziri U. Bacterial profile and current distribution of antimicrobial susceptibility patterns of uropathogens from pregnant women with urinary tract infections. IJBR. 2018 Aug; 9(8):293-9. 
23. Kolawole AS, Kolawole OM, Kandaki-Olukemi YT, Babatunde SK, Durowade KA, Kolawole CF. Prevalence of urinary tract infections (UTI) among patients attending Dalhatu Araf Specialist Hospital, Lafia, Nasarawa state, Nigeria. International journal of medicine and medical sciences. 2010 May 30; 1(5):1637.

\begin{tabular}{|c|c|c|c|}
\hline \multicolumn{4}{|c|}{ AUTHORSHIP AND CONTRIBUTION DECLARATION } \\
\hline Sr. \# & Author(s) Full Name & Contribution to the paper & Author(s) Signature \\
\hline 1 & Mahjabeen Yaseen & $\begin{array}{l}\text { Conception, Design, Drafting } \\
\text { Final approval and accountable } \\
\text { for accuracy. }\end{array}$ & \\
\hline 2 & Sadia Rashid & $\begin{array}{l}\text { Conception, Design, Drafting } \\
\text { Final approval and accountable } \\
\text { for accuracy. }\end{array}$ & \\
\hline 3 & Shagufta Naqvi & $\begin{array}{l}\text { Conception, Design, Drafting } \\
\text { Final approval and accountable } \\
\text { for accuracy. }\end{array}$ & \\
\hline
\end{tabular}

